\title{
Environmental Catastrophes and Recoveries in the Holocene
}

LoNDON, AUg. 28 - SEPT. 2, 2002

Organised by the Department of Geography \& Earth Sciences at Brunel University, this meeting brought together 150 participants from 27 countries representing a startling range of disciplines and a myriad of topics. The majority of the delegates were geographers, geologists, archaeologists and anthropologists,

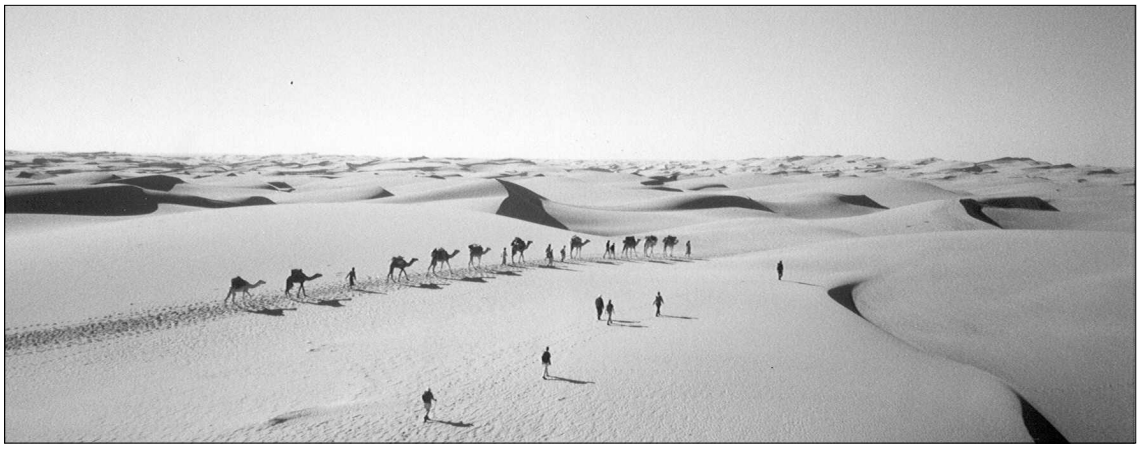

Fig. 1: Camel caravan in the Mauritanian Sahara. Camels were introduced in the Sahara around $A D$ 100. They rapidly replaced horses and oxen as the climate became drier in the following centuries (Photo: S. Leroy).

but amongst them mingled historians, astrophysicists, ecologists and health experts. Five key themes of the conference were geological, ecological, climatic, and health catastrophes and civilisation collapse. Specific topics included linkages between major volcanic eruptions recorded in the Greenland ice core with a plague in Ancient Rome, civilisation collapse in the Middle East and rainforest retraction in equatorial Africa 4000 years ago, and recent climatic downturns and the incidence of modern droughts such as that of Dustbowl America in the 1920s. Such topics ensured great media interest, with Nature, Science and New Scientist being amongst those picking up on conference highlights, such as the controversial reappraisal of the 1908Tunguska cometary impact in Siberia, new ideas on a cometary mega-tsunami that devastated eastern Australia several thousand years ago, and the politics of an earthquake fault that lies below Salt Lake City's recently constructed Olympic Stadium.

Bringing together such a rich diversity of researchers was one of the main objectives of the convenors, Professor Suzanne Leroy and Dr lain Stewart. Breaking down the human actions and the evaluation of their impact on our past and future societies. The immediate implication of such analyses is to put in a wider time perspective the events that occur at the moment (floods, fires, hurricanes, earthquakes, epidemics, extinctions) and be ready (if possible) for the extreme ones. In stark contrast to the contemporaneous Earth Summit in Johannesburg, where the discussion was about how humans are wreaking environmental havoc usual barriers between scientific communities to forge a new mix of people was a real challenge, but one that seems to have been at the heart of the meeting's success. The broad sweep of the conference was about abrupt environmental changes that had affected the planet in the last 10,000 years, whether on an otherwise balanced and passive Earth, attendees at the Brunel conference instead discussed a naturally variable and frequently harmful environment in which humans were often incidental.

So what of the future? The conference will spawn a number of publications and a follow-up session is planned at the INQUA congress in Reno, USA in July, 2003. However the main legacy of the Brunel meeting will be a new INQUA-sponsored research initiative that will build on the energies and synergies generated by the London meeting. That initiative aims to galvanise a new interdisciplinary research community to engage more closely with policy makers in disentangling the natural and human influences on environmental change, and in acknowledging the 'dark side of nature'.

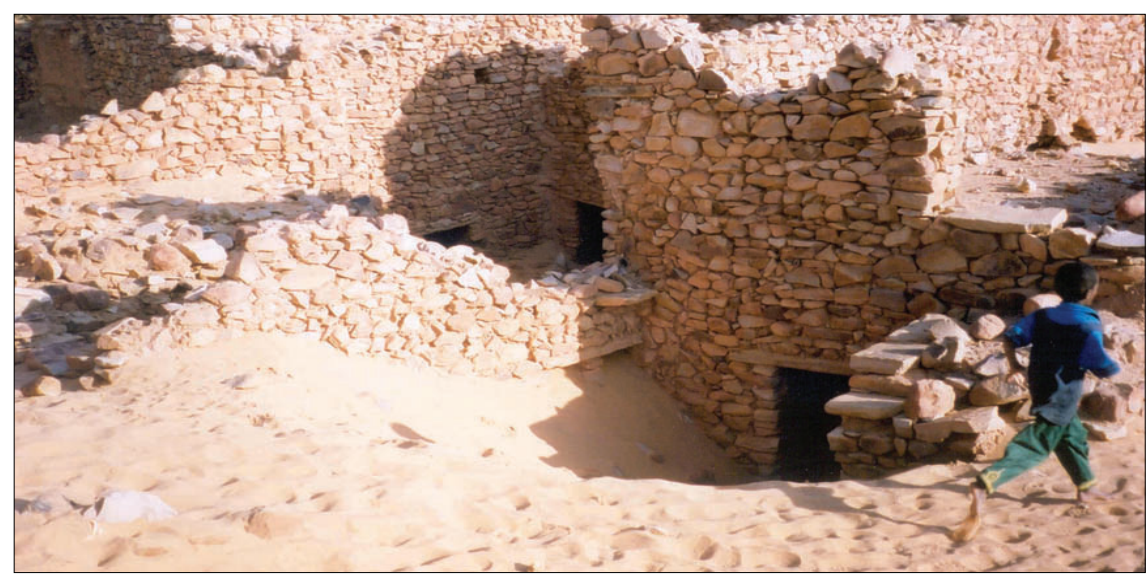

Fig. 2: Chinguetti (in the Mauritanian Sahara) is the seventh holiest city of Islam and a World Heritage site of the UNESCO since 1996. The city was created as a stop-over for the caravan trade (mostly salt). Chinguetti (XIIIth c.) was borne from the previous town of Abbere, that existed already in the VIII ${ }^{\circ}$ C. but disappeared under the sands. Chinguetti's heydays were between XVII and $X I X{ }^{\circ} \mathrm{C}$. Several levels of this ancient city are now below the sand. In the whole area, desperate measures (such as dune stabilisation by planting of hedges and reforestation by introduction of Prosopis juliflora trees) have been made, with the help of international organisations, to stop the sand invasion, but too often with little success (Photo: S. Leroy).

these changes reflected natural or The meetings sponsors included PAGES, INQUA, The British Academy, IUGS-Geoindicators, and IUGS-SOTSPI.

More on our web site: http: //www.brunel.ac.uk/deptsgeo/ Catastrophes/. Abstracts are available on the website: http://atlasconferences.com/c/a/i/q/01.htm

\section{Suzanne Leroy and IaIn Stewart \\ Brunel University, London UK, suzanne.leroy@brunel.ac.uk iain.stewart@brunel.ac.uk}

